\title{
chaOPEN
}

\section{Health care utilization in medically complex people living with HIV before and after admission to an HIV-specific community facility: a pre-post comparison study}

\author{
Ann Stewart MD, Tony Antoniou PhD, Erin Graves MSc, Lesley Plumptre PhD, Soo Chan Carusone PhD
}

\section{Abstract}

Background: People living with HIV and multiple comorbidities have high rates of health service use. This study evaluates system usage before and after admission to a community facility focused on HIV care.

Methods: We used Ontario administrative health databases to conduct a pre-post comparison of rates and costs of hospital admissions, emergency department visits, and family physician and home care visits among medically complex people with HIV in the year before and after admission to Casey House, an HIV-specific hospital in Toronto, for all individuals admitted between April 2009 and March 2015. Negative binomial regression was used to compare rates of health care utilization. We used Wilcoxon rank sum tests to compare associated health care costs, standardized to 2015 Canadian dollars. To contextualize our findings, we present rates and costs of health service use among Ontario residents living with HIV.

Results: During the study period, 268 people living with HIV were admitted to Casey House. Emergency department use declined from 4.6 to 2.5 visits per person-year $(p=0.02)$ after discharge from Casey House, and hospitalization rates declined from 1.4 to 1.1 admissions per person-year $(p=0.05)$. Conversely, home care visits increased from 24.3 to 35.6 visits per person-year $(p=0.01)$ and family physician visits increased from 18.3 to 22.6 visits per person-year $(p<0.001)$ in the year after discharge. These changes were associated with reduced overall costs to the health care system. The reduction in overall costs was not significant $(p=0.2)$; however, costs of emergency department visits $(p<0.001)$ and physician visits $(p<0.001)$ were significantly less.

Interpretation: Health care utilization by people with HIV was significantly different before and after admission to a community hospital focused on HIV care. This has implications for health care in other complex patient populations.

\footnotetext{
mprovements in HIV care have reduced disease-related morbidity and mortality for many people living with HIV. ${ }^{1-3}$ However, several studies have shown that these benefits have not been incurred equitably, with medically complex and socioeconomically marginalized people with HIV deriving less benefit from advances in HIV care. ${ }^{3-9}$ For these individuals, social and structural barriers to HIVspecific care, including comorbid mental health illness, homelessness, food insecurity and poverty, converge to create conditions promoting high rates of health service use. ${ }^{10-13}$

Casey House is a community hospital in Toronto that provides care for medically and socially complex people with HIV. ${ }^{14-16}$ In 2017, Casey House received provincial funding to open a day health program, co-located with the inpatient program, expanding its outpatient services to improve health care access and outcomes related to prevention and management of illness in people with HIV. Understanding the pattern and intensity of health care use among clients of Casey House was critical to inform the design and implementation, and projected impact of this novel program. ${ }^{14-16}$
}

Therefore, we conducted a pre-post comparison study of health service use and associated costs among people with HIV in the year preceding admission to and the year after discharge from Casey House. For context, we examined the health service use and costs of a cohort of Ontario residents with HIV. We speculated that, because of comprehensive discharge planning, rates of ambulatory care and home-based services would increase after discharge from Casey House, with corresponding declines in the use of acute care services.

Competing interests: Ann Stewart holds a grant from Gilead Pharmaceuticals, for research on hepatitis $C$, outside the submitted work. Soo Chan Carusone is employed by Casey House as director of research. No other competing interests were declared.

This article has been peer reviewed.

Correspondence to: Ann Stewart, Ann.Stewart@UnityHealth.to CMAJ Open 2021. DOI:10.9778/cmajo.20200024 


\section{Methods}

\section{Study design and setting}

We conducted a pre-post comparison study of health service use and related costs at Casey House, a community hospital in downtown Toronto that cares exclusively for people with HIV. At the time of study, Casey House was a 13-bed facility offering both respite and subacute care. People with HIV can be admitted to Casey House for palliative care, for recovery and rehabilitation from recent acute care admission, for failure to cope in the community or frail health, and for instances of a psychosocial crisis.

There are several differences between the services offered at Casey House and acute hospitals, including the provision of alternative forms of care (e.g., massage therapy), extended lengths of stay for convalescence and rehabilitation, higher nursing-to-patient ratios, and education and peer support to promote recovery. Care is delivered by a multidisciplinary team that includes rehabilitation, nursing, social work and pharmacy professionals, and emphasizes attention to social determinants of health, including housing instability and access to mental health supports. Discharge planning includes antiretroviral therapy prescriptions and a follow-up appointment with a family physician or HIV specialist within 7 days of discharge.

\section{Data sources}

We used Ontario's administrative databases, held at ICES, to identify people with HIV admitted to Casey House between Apr. 1, 2009, and Mar. 31, 2015.

We identified individuals admitted to Casey House using the Canadian Institute for Health Information's Discharge Abstract Database (DAD), which contains detailed clinical records on all hospital admissions in Ontario. In cases where individuals were admitted on more than 1 occasion, we studied only the first admission. Individuals included in our primary analysis had universal access to physician services and hospital care, and more than $80 \%$ had prescription drug coverage through the Ontario Drug Benefit Plan.

We identified people with HIV not admitted to Casey House using the Ontario HIV Database, an administrative data registry of Ontario residents with diagnosed HIV infection, which was generated using a validated case-finding algorithm. The definition of 3 physician claims with an International Classification of Diseases, Ninth Revision code for HIV infection $(042,043,044)$ within a 3 -year period has a sensitivity and specificity of $96.2 \%$ (95\% confidence interval [CI] $95.2 \%-97.9 \%$ ) and $99.6 \%$ (95\% CI 99.1\%-99.8\%), respectively, for identifying people living with HIV. ${ }^{17}$

We identified claims for physician services by physician specialty using the Ontario Health Insurance Plan database. We used the Registered Persons Database, a registry of all Ontario residents eligible for health insurance, for basic demographic and date-of-death data. We obtained information regarding hospital admissions and emergency department visits in the year preceding Casey House admission and the year after discharge using the DAD and National Ambulatory
Care Reporting System Database, respectively. All data sets were linked using unique, encoded identifiers and were analyzed at ICES.

\section{Outcomes}

Our main outcome was a comparison of health service use and associated costs (standardized to 2015 Canadian dollars) in the year preceding admission to Casey House and the year after discharge from Casey House. Consequently, the dates of admission and discharge were the index dates for determining preadmission and postdischarge health service use, respectively. We specifically compared preadmission and postdischarge rates of hospital admissions, emergency department visits, outpatient physician visits and home care use. Outcomes are presented in person-years to account for those who died before a full year. We also examined publicly funded medication costs during these periods.

We ascertained associated individual-level health care costs with a costing algorithm available at ICES. ${ }^{18}$ Total costs included hospitalizations, outpatient clinic visits, same-day surgery, emergency department visits, dialysis clinic visits, cancer clinic visits, publicly funded drugs, inpatient rehabilitations, complex and continuing care, home care services, physician visits, laboratory claims, nonphysician billings, capitation costs for primary care patient enrolment models, long-term care and inpatient mental health hospitalizations.

The ICES costing algorithm attributes costs to individuals by identifying each encounter with the health care system and attaching unit costs to services used within the encounter. The algorithm covers direct costs to the province only. Costs were standardized to 2015, the final year of data analyzed.

To contextualize our findings, we computed health service use and associated costs of care for Ontario residents with HIV. To do this, we randomly assigned each person from the general population of people with HIV index dates based on the distribution of admission dates of the Casey House clients, and determined their health service use and associated costs in the year preceding this date.

\section{Statistical analysis}

We summarized patient characteristics using descriptive statistics. Rates of health care use were examined as events per personyear. We used the Johns Hopkins Adjusted Clinical Groups (ACG) Case-Mix System to describe the baseline comorbidity burden of Casey House clients and the general population of Ontario residents with HIV. In this study, we used Aggregated Diagnosis Groups (ADGs), which are clusters of diagnostic codes that are similar in terms of severity and expected persistence. The number of ADGs ranges from 0 to a maximum of 32 , with a higher number reflecting a higher level of comorbidity. ${ }^{19}$ This system has been validated for use in Canadian populations. ${ }^{20} \mathrm{We}$ used negative binomial regression for pre-post comparisons of health care utilization rates and Wilcoxon rank sum tests for pre-post comparisons of health care costs.

Because our administrative databases do not contain key data (e.g., homelessness and food insecurity) needed to conduct a matched analysis of Casey House clients with the general 
HIV cohort, we replicated our analyses using only those individuals with the greatest predicted health care needs, defined using resource utilization bands. Resource utilization bands were derived using the Johns Hopkins ACG system. We reasoned that these individuals would be more alike in terms of baseline levels of medical need, allowing us to discern whether regression to the mean was contributing to changes in health care use observed among Casey House clients after discharge from Casey House.

\section{Ethics approval}

The use of data in this project was authorized under section 45 of Ontario's Personal Health Information Protection Act, which does not require review by a research ethics board.

\section{Results}

We studied data on 268 people with HIV who were admitted to Casey House between Apr. 1, 2009, and Mar. 31, 2015 (Table 1). The mean age was 48.7 (standard deviation 10.1) years, and $82.8 \%$ were male. Compared with the general population of people with HIV, clients of Casey House had a greater comorbidity burden. In addition, clients of Casey House had higher rates of emergency department visits (4.6 v. 0.7 visits per person-year), hospital admissions ( 1.4 v. 0.1 admissions per person-year), specialist visits (46.2 v. 7.0 visits per person-year) and family physician visits (18.3 v. 6.3 visits per person-year) than the general population of adults with HIV. Overall, Casey House clients incurred total health care costs that were fivefold those of the general population of people with HIV during this period (\$58610 v. \$12030 per person-year), driven largely by costs related to inpatient admissions ( $\$ 28340 \mathrm{v}$. $\$ 2050$ per person-year) and emergency department visits (\$1690 v. \$200 per person-year).

In our main analysis, we observed a change in health care use among clients of Casey House in the year before and year after admission (Table 2). Specifically, rates of emergency department visits declined from 4.6 to 2.5 visits per personyear $(p=0.02)$ and rates of hospital admissions declined from 1.4 to 1.1 admissions per person-year $(p=0.05)$. Similarly, rates of visits to specialist physicians among Casey House clients declined from 46.2 to 31.8 visits per person-year $(p=0.2)$. Conversely, rates of family physician visits increased from 18.3 to 22.6 visits per person-year $(p<0.001)$ and home care visits increased from 24.3 to 35.6 visits per person-year $(p=0.01)$.

Changes in service utilization among clients of Casey House translated into changes in associated health care costs per person-year (Table 2). Overall total costs to the health care system among Casey House clients declined from $\$ 58610$ to $\$ 51720$ per person-year, but this reduction was not significant $(p=0.2)$. Declines in costs were associated with emergency department visits ( $\$ 1690$ to $\$ 880$ per person-year,

\begin{tabular}{|c|c|c|c|}
\hline \multirow[b]{2}{*}{ Covariate } & \multicolumn{2}{|c|}{ No. (\%) of participants* } & \multirow[b]{2}{*}{$\begin{array}{c}\text { Standardized } \\
\text { difference }\end{array}$} \\
\hline & $\begin{array}{l}\text { Casey House clients } \\
\qquad n=268\end{array}$ & $\begin{array}{l}\text { Ontario residents with HIV } \\
\qquad n=19765\end{array}$ & \\
\hline Age, yr, mean \pm SD & $48.7 \pm 10.1$ & $46.0 \pm 11.6$ & 0.25 \\
\hline \multicolumn{4}{|l|}{ Sex } \\
\hline Female & $46(17.2)$ & $3971(20.1)$ & 0.08 \\
\hline Male & $222(82.8)$ & 15794 (79.9) & 0.08 \\
\hline \multicolumn{4}{|c|}{ Eligibility for provincial drug coverage } \\
\hline No & $32(11.9)$ & $10064(50.9)$ & 0.93 \\
\hline Yes & $219(81.7)$ & $8510(43.1)$ & 0.87 \\
\hline Age $>65 \mathrm{yr}$ & $17(6.3)$ & $1191(6.0)$ & 0.01 \\
\hline \multicolumn{4}{|c|}{ Aggregated Diagnosis Groups } \\
\hline Mean \pm SD & $12.5 \pm 4.1$ & $5.6 \pm 4.3$ & 1.65 \\
\hline 0 & $1-5 \dagger$ & $3096(15.7)$ & 0.59 \\
\hline $1-4$ & $3-7 \dagger$ & $5677(28.7)$ & 0.77 \\
\hline $5-9$ & $47(17.5)$ & $7314(37.0)$ & 0.45 \\
\hline $10-14$ & $129(48.1)$ & $3012(15.2)$ & 0.76 \\
\hline$\geq 15$ & $84(31.3)$ & $666(3.4)$ & 0.79 \\
\hline $\begin{array}{l}\text { Note: } \mathrm{SD}=\text { standard devi } \\
\text { *Unless stated otherwise. } \\
\text { †These cells have been }\end{array}$ & limiting the reporting $\mathrm{o}$ & sizes. & \\
\hline
\end{tabular}




\begin{tabular}{|c|c|c|c|c|c|c|}
\hline \multirow[b]{2}{*}{ Variable } & \multicolumn{3}{|c|}{$\begin{array}{l}\text { Health care utilization } \\
\text { (events per person-year) }\end{array}$} & \multicolumn{3}{|c|}{$\begin{array}{c}\text { Health care cost } \\
(\$ \text { per person-year })^{\star}\end{array}$} \\
\hline & $\begin{array}{l}1 \text { year before } \\
\text { admission }\end{array}$ & $\begin{array}{l}1 \text { year after } \\
\text { discharge }\end{array}$ & $p$ value & $\begin{array}{l}1 \text { year before } \\
\text { admission }\end{array}$ & $\begin{array}{c}1 \text { year after } \\
\text { discharge }\end{array}$ & $p$ value \\
\hline Inpatient hospitalizations & 1.4 & 1.1 & 0.05 & 28340 & 23690 & 0.02 \\
\hline Emergency department visits & 4.6 & 2.5 & 0.02 & 1690 & 880 & $<0.001$ \\
\hline \multicolumn{7}{|l|}{ Physician visits } \\
\hline All physicians & 70.3 & 58.8 & 0.04 & 6090 & 3750 & $<0.001$ \\
\hline Family physicians & 18.3 & 22.6 & $<0.001$ & & & \\
\hline Specialists & 46.2 & 31.8 & 0.2 & & & \\
\hline Home care services & 24.3 & 35.6 & 0.01 & 2210 & 2970 & 0.004 \\
\hline Publicly funded drugs & & & & 12750 & 15180 & 0.002 \\
\hline Total cost $\dagger$ & & & & 58610 & 51720 & 0.2 \\
\hline
\end{tabular}

$p<0.001$ ), hospital admissions (\$28 340 to $\$ 23690$ per person-year, $p=0.02$ ) and physician billings to OHIP ( $\$ 6090$ to $\$ 3750$ per person-year, $p<0.001)$. In contrast, spending on home care services $(\$ 2210$ to $\$ 2970$ per person-year, $p=$ $0.004)$ and publicly funded prescription drugs (\$12750 to $\$ 15180$ per person-year, $p=0.002$ ) increased among clients of Casey House in the year after discharge relative to the year preceding admission.

In our sensitivity analysis of individuals in the highest resource utilization band (Appendix 1, available at www.cmaj open.ca/content/9/2/E460/suppl/DC1), we found postdischarge declines in rates of hospitalization and emergency department visits of $25.8 \%$ and $48.4 \%$, respectively, for Casey House clients $(n=210)$. Respective declines for the general population of people with HIV $(n=3156)$ in the year after their index date were $29.3 \%$ and $30.9 \%$.

\section{Interpretation}

In our study, we found changes in health care use and associated spending among socially and medically complex people with HIV following an admission to Casey House. Specifically, rates of hospital admissions, emergency department visits and specialist visits declined in the year after discharge, with corresponding decreases in costs related to emergency department use and physician billings. Conversely, family physician visits and home care use increased after discharge, with increases in costs for publicly funded prescription medications and home care services.

These findings likely reflect the high comorbidity burden of Casey House clients, including a high prevalence of mental health conditions and substance use disorders. ${ }^{14,15}$ Prior research has shown that people with HIV and coexisting mental health conditions have higher rates of health service use and costs relative to people with HIV without mental health conditions. For example, a study involving more than 14000 people with HIV who were members of the Kaiser Permanente Health Northern California health care plan between 1995 and 2010 found higher mean total health costs for people with HIV and concomitant mental health and substance use disorders relative to people with HIV lacking these conditions (US\$32 881 v. US\$29 142 per patient per year). ${ }^{21}$ Similar findings were observed in studies involving people with HIV receiving care through Medicaid and the US Veterans Health Administration. ${ }^{22,23}$

In addition to a high comorbidity burden, clients of Casey House often have advanced HIV disease at the time of admission, as defined by the World Health Organization, ${ }^{24}$ which has been shown in other studies to increase health care costs. ${ }^{22,23,25}$ Specifically, more than half of the clients admitted in 2008 had CD4 cell counts less than 200 cells $/ \mathrm{mm}^{3}$, and opportunistic infections were common. ${ }^{15}$ Finally, Casey House clients face challenges associated with unstable housing, food insecurity and poverty, all of which have been shown in prior studies to increase health service use among people with HIV. ${ }^{11,21,26}$ Taken together, we speculate that advanced illness, mental health comorbidity and social determinants of health intersect among Casey House clients to create conditions facilitating greater health service need and costs.

Although we cannot assume that a causal relation exists between Casey House admission and the observed changes, it is reasonable to infer that the nature of services provided influenced the health service use in the year after discharge. Most notably, we speculate that the increase in community physician visits and home care use reflects the provision of 
appointments to local family physicians who specialize in HIV care and home care referrals before Casey House discharge. In addition, admission to Casey House may change care pathways owing to enhanced allied health team supports, social connection for clients, focused physician evaluation and team encouragement of medication adherence. Ongoing visits by Casey House nurses after discharge provide support with medication adherence and physician follow-up. These increased community supports may redirect clients from emergency departments.

We also found significant reductions in costs attributable to physician billings and emergency department use after discharge from Casey House. Although some of these declines may be related to deaths of individuals after discharge, the costs incurred by end-of-life care would be accounted for in our calculations.

\section{Limitations}

Several limitations of our study merit emphasis. First, we used administrative health data and did not have access to laboratory data, including viral load and CD4 cell count. In addition, we did not have detailed information on specific determinants of health, such as food and housing instability. However, the finding that more than $80 \%$ of Casey House clients qualified for provincial drug coverage shows that these individuals represent an especially socioeconomically disadvantaged segment of people with HIV.

It is possible that regression to the mean contributed to the decrease in utilization postdischarge, particularly when viewed in light of our sensitivity analysis finding reductions in rates of hospitalization in Casey House clients and the general population of people with HIV in the highest resource utilization bands. However, it is unlikely that regression to the mean fully explains our findings, given postdischarge increases in rates of home care and primary care physician visits observed only among Casey House clients, and findings from the sensitivity analysis of more pronounced reductions in emergency department use among Casey House clients relative to the general population of people with HIV.

Because Casey House clients differ from the general population of people with HIV in important determinants of health that cannot be accounted for using administrative data, we were unable to conduct a matched study comparing health service use between these 2 groups. However, this was not the intent of our study, which was to determine the pattern and intensity of health care utilization, and associated costs, of adults living with HIV before and after admission to Casey House. We used data from the general population to provide a benchmark of health service use and costs of care for a typical person with HIV in Ontario over a given year, providing important context. Finally, our study reflects patterns of health service use through 2015 and may not capture the impacts of changes to Casey House services since that time, including a new facility and outpatient day program. Evaluation of these changes are next steps in our research program.

\section{Conclusion}

Patterns of health care use and costs among medically and socially complex people with HIV changed after admission to and discharge from a hospital specializing in HIV care, including reductions in certain costs. These findings have implications for other complex, high-cost patient populations. Further research examining the mechanisms through which such specialized care affects health care use and other social determinants is necessary to address ongoing gaps in care and further optimize the health of this vulnerable population.

\section{References}

1. Antiretroviral Therapy Cohort Collaboration. Life expectancy of individuals on combination antiretroviral therapy in high-income countries: a collaborative analysis of 14 cohort studies. Lancet 2008;372:293-9.

2. Marcus JL, Chao CR, Leyden WA, et al. Narrowing the gap in life expectancy between HIV-infected and HIV-uninfected individuals with access to care. 7 Acquir Immune Defic Syndr 2016;73:39-46.

3. Patterson S, Cescon A, Samji H, et al. Life expectancy of HIV-positive individuals on combination antiretroviral therapy in Canada. BMC Infect Dis 2015;15:274.

4. Martin LJ, Houston S, Yasui Y, et al. All-cause and HIV-related mortality rates among $\mathrm{HIV}$-infected patients after initiating highly active antiretroviral therapy: the impact of aboriginal ethnicity and injection drug use. Can 7 Public Health 2011;102:90-6.

5. Schwarcz SK, Hsu LC, Vittinghoff E, et al. Impact of housing on the survival of persons with AIDS. BMC Public Health 2009;9:220.

6. Weiser SD, Yuan C, Guzman D, et al. Food insecurity and HIV clinical outcomes in a longitudinal study of urban homeless and marginally housed HIV-infected individuals. AIDS 2013;27:2953-8.

7. Khanijow K, Hirozawa A, Ancock B, et al. Difference in survival between housed and homeless individuals with HIV, San Francisco, 2002-2011.7 Health Care Poor Underserved 2015;26:1005-18.

8. Ickovics JR, Hamburger ME, Vlahov D, et al. Mortality, CD4 cell count decline, and depressive symptoms among HIV-seropositive women: longitudinal analysis from the HIV Epidemiology Research Study. FAMA 2001; 285:1466-74.

9. Klein MB, Rollet-Kurhajec KC, Moodie KC, et al. Mortality in HIV-hepatitis C co-infected patients in Canada compared to the general Canadian population (2003-2013). AIDS 2014;28:1957-65.

10. Smith MY, Rapkin BD, Winkel G, et al. Housing status and health care service utilization among low-income persons with HIV/AIDS. 7 Gen Intern Med 2000;15:731-8.

11. Weiser SD, Hatcher A, Frongillo EA, et al. Food insecurity is associated with greater acute care utilization among HIV-infected homeless and marginally housed individuals in San Francisco. 7 Gen Intern Med 2013;28: 91-8.

12. Gordon AJ, McGinnis KA, Conigliaro J, et al. Associations between alcohol use and homelessness with healthcare utilization among human immunodeficiency virus-infected veterans. Med Care 2006;44(Suppl 2): S37-43.

13. Mijch A, Burgess P, Judd F, et al. Increased health care utilization and increased antiretroviral use in $\mathrm{HIV}$-infected individuals with mental health disorders. HIV Med 2006;7:205-12.

14. Carusone SC, O'Leary B, McWatt S, et al. The lived experience of the hospital discharge "plan": a longitudinal qualitative study of complex patients. 7 Hosp Med 2017;12:5-10.

15. Halman, M, Schaefer-McDaniel N, Stranks S, et al. Medical and psychiatric comorbidities: the complexity of care in a sample of patients with late-stage HIV disease. Abstract: CDB0018 July 18-23, 2010 Vienna XVIII International AIDS Conference (AIDS 2010). Available: www.abstract-archive.org/Abstract/ Share/2032 IAS 2010 (accessed 2021 Apr. 22).

16. Antoniou T, Graves E, Plumptre L, et al. Antiretroviral prescription pick-up and physician follow-up after hospital discharge among medically complex people with HIV. Open Forum Infect Dis 2019;6:ofz009.

17. Antoniou T, Zagorski B, Loutfy MR, et al. Validation of case-finding algorithms derived from administrative data for identifying adults living with human immunodeficiency virus infection. PLoS One 2011;6:e21748.

18. Wodchis W, Bushmeneva K, Nikitovic M, et al. Guidelines on person-level costing using administrative databases in Ontario: working paper series volume 1 May 2013. Toronto: Health System Performance Research Network; 2013.

19. The Johns Hopkins ACG System. Baltimore: Johns Hopkins University. Available: www.hopkinsacg.org (accessed 2019 June 21).

20. Reid RJ, MacWilliam L, Verhulst L, et al. Performance of the ACG case-mix system in two Canadian provinces. Med Care 2001;39:86-99. 
21. DeLorenze GN, Tsai AL, Horberg MA, et al. Cost of care for HIV-infected patients with co-occurring substance use disorder or psychiatric disease: report from a large, integrated health plan. Aids Res Treat 2014;2014:570546.

22. Gebo KA, Fleishman JA, Conviser R, et al. Contemporary costs of HIV healthcare in the HAART era. AIDS 2010;24:2705-15.

23. Barnett PG, Chow A, Joyce VR, et al. Determinants of the cost of health services used by veterans with HIV. Med Care 2011;49:848-56.

24. World Health Organization guidelines for managing HIV disease and rapid initiation of anti-retroviral therapy. Geneva: The World Health Organization; 2017.

25. Chen RY, Accortt NA, Westfall AO, et al. Distribution of health care expenditures for HIV-infected patients. Clin Infect Dis 2006;42:1003-10.

26. Rothbard AB, Lee S, Blank MB. Cost of treating seriously mentally ill persons with HIV following highly active retroviral therapy (HAART). 7 Ment Health Policy Econ 2009;12:187-94.

Affiliations: Department of Family and Community Medicine (Stewart, Antoniou), St. Michael's Hospital, University of Toronto; Li Ka Shing Knowledge Institute (Antoniou), St. Michael's Hospital; ICES (Antoniou, Graves, Plumptre); Casey House (Chan Carusone), Toronto, Ont.; Department of Health Research Methods, Evidence, and Impact (Chan Carusone), McMaster University, Hamilton, Ont.

Contributors: All authors were involved in conceiving the study design. Erin Graves and Lesley Plumptre managed the data abstraction and analysis from the clinical database. Soo Chan Carusone participated in refining the questions and analyzing the data. Tony Antoniou and Ann Stewart drafted the manuscript. All authors critically reviewed the manuscript, gave final approval of the version to be published and agreed to be accountable for all aspects of the work.
Funding: This study was funded as an Applied Health Research Question through ICES, which is funded by an annual grant from the Ontario Ministry of Health.

Content licence: This is an Open Access article distributed in accordance with the terms of the Creative Commons Attribution (CC BY-NC-ND 4.0) licence, which permits use, distribution and reproduction in any medium, provided that the original publication is properly cited, the use is noncommercial (i.e., research or educational use), and no modifications or adaptations are made. See: https://creativecommons.org/licenses/by-nc-nd/4.0/

Data sharing: Data for this project were obtained through an Applied Health Research Question (AHRQ) project at ICES. All AHRQ project summaries are posted on the website (AHRQ Projects, https://www.ices. on.ca/DAS/AHRQ/AHRQ-Projects). Members of the public can request to view an AHRQ deliverable via an application and adjudication process. This is initiated with an email to ahrq@ices.on.ca.

Disclaimer: The sponsors had no role in the design or conduct of the study; in the collection, analysis or interpretation of the data; or in the preparation, review or approval of the manuscript. The opinions, results, and conclusions reported in this paper are those of the authors and are independent from the funding source. No endorsement by ICES or the Ontario Ministry of Health is intended or should be inferred.

Supplemental information: For reviewer comments and the original submission of this manuscript, please see www.cmajopen.ca/content/9/2/ E460/suppl/DC1. 